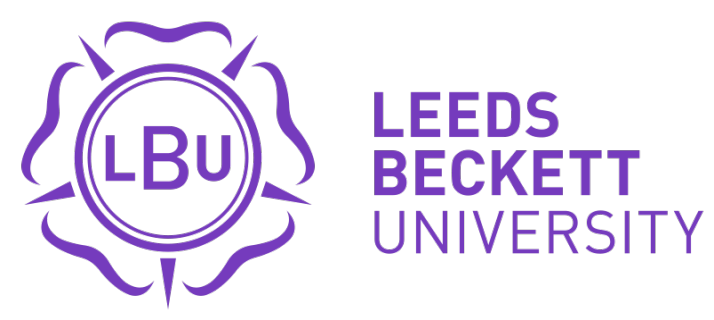

Citation:

Trevorrow, P and Fabri, M (2013) Running to behavior change. Lecture Notes in Computer Science (including subseries Lecture Notes in Artificial Intelligence and Lecture Notes in Bioinformatics), 8014 L (PART 3). pp. 585-593. ISSN 0302-9743 DOI: https://doi.org/10.1007/978-3-642-39238-2_64

Link to Leeds Beckett Repository record:

https://eprints.leedsbeckett.ac.uk/id/eprint/5656/

Document Version:

Article (Accepted Version)

The aim of the Leeds Beckett Repository is to provide open access to our research, as required by funder policies and permitted by publishers and copyright law.

The Leeds Beckett repository holds a wide range of publications, each of which has been checked for copyright and the relevant embargo period has been applied by the Research Services team.

We operate on a standard take-down policy. If you are the author or publisher of an output and you would like it removed from the repository, please contact us and we will investigate on a case-by-case basis.

Each thesis in the repository has been cleared where necessary by the author for third party copyright. If you would like a thesis to be removed from the repository or believe there is an issue with copyright, please contact us on openaccess@leedsbeckett.ac.uk and we will investigate on a case-by-case basis. 


\title{
Running to Behavior Change
}

\author{
Pip Trevorrow and Marc Fabri \\ Leeds Metropolitan University, Leeds, UK \\ (P.Trevorrow@leedsmet.ac.uk, M.Fabri@leedsmet.ac.uk )
}

\begin{abstract}
Levels of overweight and obese individuals have been seen as rising across the globe. This has caused concerns with regard to how active individuals are and realization that a high percentage of the population do not meet the weekly requirement of physical activity. Current focus has been on the capabilities that new technologies can offer as an intervention technique. This paper offers an initial investigation into one such technology, namely the iPod Nike+ kit, which acts as a tracker for running behaviors. This scoping study was conducted via a questionnaire and analysis of customer reviews. Participants were assessed on their stage of change for physical activity behavior, based on the Transtheoretical Model of Change (TTM), before and after using the technology. The results from this study showed that the technology was received positively from those who used it and the predominant outcome was that individuals were more enthusiastic about running.
\end{abstract}

Keywords: Behavior change, physical activity, iPod Nike+ kit, Transtheoretical Model of Change

\section{Introduction}

Levels of overweight and obese individuals have been seen as increasing across the globe. The World Health Organisation [1] has identified obesity as being the fourth highest contributor to premature death. Numbers of obese children have also been seen as increasing in developed countries [2]. Being overweight or obese can lead to a number of health related diseases, such as diabetes, heart disease and musculoskeletal disorders; these have all been seen to be reduced through physical activity $[1,3,4]$.

In the UK the Government have commissioned reports and White Papers specifically related to improving healthy lifestyles [5-7]. In addition campaigns such as Everyday Sport and Change4Life have been promoted as part of the Government initiative to get more people active and aware of healthy behaviors $[8,9]$.

Being physically active is seen to have benefits for all groups of society, in addition to reducing the costs that health related diseases can accrue $[3,10]$. The recommended level of physical activity has been set as [1]: 
- 5-17 year olds: at least 60minutes of moderate to vigorous intensity on a daily basis. Vigorous intensity should be incorporated at least three times per week

- 18-64 year olds: at least 150minutes of moderate intensity throughout the duration of the week; or at least 75 minutes of vigorous intensity throughout the week; this should also include muscle strengthening activities on two or more days throughout the week

- 65+: as for 18-64 year olds but with some adjustments based on the frailty of the individual

However, despite the many benefits that being physically active can provide an increasing number of the population are largely sedentary [3] and do not meet the stated recommendation for activity levels [8, 11]. Sedentary lifestyles, amongst other factors have been seen as contributing to the rise in weight levels [2]. The activity habits of children have been seen as particularly affected by the increase in technology entertainment through activities such as video games and playing on computers [2, 12].

More recently researchers have been investigating whether technology could become part of a solution rather than a contributing factor [2, 12, 13]. Technologies such as pedometers, mobile phones and heart rate monitors are being used to encourage participation and performance in physical activity [13]. Interactive games such as Nintendo Wii and Dance Dance Revolution have entered the market, requiring some form of body movement to play the game. Whilst not deemed to be as high in energy expenditure as actually participating in some form of sport or exercise, they have the potential to increase activity levels for some [2].

With an increase in the capabilities of technologies related to healthy behaviors, the authors looked into the potential to utilize them in order to change behaviors with regard to physical activity. The focus of the research collected for this paper was on the activity of running; obviously there are other forms of exercise that have similar related new technologies to potentially encourage behavior change to activity habits, however, running is something that perhaps is more available to the majority of the population. Running is potentially one of the cheapest, most accessible forms of exercise to get involved in; a good pair of trainers is all the equipment that is really required.

\section{Use of TTM}

The Transtheoretical Model (TTM) of change has been used extensively with regard to behavioral change for health and physical activity $[14,15]$. The TTM arose from a need to understand how individuals change behavior rather than the more popular topic at the time of its development of why people do not change $[4,16,17]$. The TTM includes four concepts that are crucial to the ultimate aim of behavioral change; these are stages of change, processes of change, self-efficacy and decisional balance [15]. The stages of change are identified as follows $[16,18]$ : 
1. Precontemplation - the individual is not ready for change and has not considered change

2. Contemplation - the individual is thinking about changing but has not started anything

3. Preparation - the individual has decided to change their behavior and is getting ready for the change

4. Action - the individual is actively partaking in changing the problem behavior

5. Maintenance - the individual has adopted the behavioral change and has sustained this for more than 6 months

The model is cyclical in nature as individuals can relapse and re-enter at any one of the previous stages [16].

The processes of change must be accomplished in order for the individual to progress from one stage to the next. The processes required are dependent on the stage that the individual is currently within. Ten processes were identified from investigating specific techniques of behavior change in other theories, the most important ones were identified and applied to the TTM [16]. The processes can be divided into experiential processes, which relate to personal awareness of how the change in behavior will help, and behavioral processes, which involves actual activity by the individual [14].

Decisional balance involves the individual being aware of the advantages of changing their problem behavior and believing that these advantages outweigh the disadvantages. Self-efficacy is the personal belief that the individual can avoid temptation and can maintain the change to their behavior [18].

The TTM will be applied to the pilot study data in order to ascertain the impact of the iPod Nike+ kit technology on the participants with regard to behavior change.

\section{Encouraging Physical Activity}

Whilst not the main focus of the paper, it was deemed appropriate to include a brief discussion of potential factors that have been seen to help individuals to start or continue physical activity. These are not specifically related to technology as they stand but can be used to help inform the design of such technologies for the use of behavioral change.

Social support has been seen as having an impact on continuing physical activity, although it is claimed to be more influential on women than men [19].

Goal setting is perceived to have an impact on change with regard to physical activity [20]; for example, setting a particular step count for the day or week. If the individual combines goal setting with monitoring their performance this is believed to enhance behavioral change with regard to physical activity [21].

Receiving messages that are specific to the individual is considered to increase the likelihood that the message is read and also then applied to personal behavioral change $[12,21]$. However, literacy is something that may 
need to be considered when targeting a wide proportion of the population, spoken messages are thus considered as beneficial for such groups or indeed for those who may prefer such communication techniques rather than the written word [12].

Obviously there are many barriers to getting involved in physical activity, to name but a few, other demands, tiredness, potential costs, safety and lack of interest are just a few that can inhibit the uptake of exercise [22]. With regard to running specifically the environment can be a big issue especially if running alone, the weather and daylight hours can impinge upon running in public spaces [22].

The focus of this paper is on the potential of new technologies, specifically the iPod Nike+ kit, to enhance and overcome the above points and ultimately encourage individuals to become or continue being physically active.

\section{Technology Used for Behavior Change with Regard to Physical Activity}

With the increase in weight levels and sedentary behavior across the globe, the entertainment industry was highlighted by the Department of Health and Human Services as a potential area for increasing activity levels and hence reduce weight issues $[11,23]$.

By utilizing the ever increasing capabilities of technology to act as interventions for physical activity, the time and cost pressure such processes can place on health care organizations can potentially be alleviated. Further, technology can have a wider, faster reach than conventional interventions. Recruitment and delivery of such interventions can be highly increased through the use of technology [12]. Technologies such as mobile phones, personal digital assistants (PDAs), websites and many other formats have the potential to provide such interventions [3].

Recruitment can be considered as proactive, where participants are contacted directly, or reactive, where participants act on the basis of advertisements. The use of technology feeds into recruitment via the proactive method on a potentially large scale [12]; thus reaching those who may be in the precontemplation stage of the TTM, in addition to the other stages of behavioral change, which a reactive approach may miss.

Mobile phone technology, namely the use of SMS texting, was used as an intervention method for encouraging physical activity amongst postnatal women [24]. The intervention was focused on increasing walking and intensity of activity for the participants. The study found an increase in self-efficacy and goal setting; however physical activity did not significantly change.

Cavallo et al [19] conducted an intervention study using Facebook as a potential social support mechanism to encourage physical activity uptake and maintenance. The study showed that although there was no immediate increase in social support perceptions or physical activity in the participants, the 
medium of social networks such as Facebook had great potential for delivering interventions to young people.

A review of research on active video games conducted by Foley and Maddison [2] showed that the level of intensity and time attributed to such activities did not add up to the recommended physical activity levels. However, it was by far an improvement on purely sedentary activities. Such games have the potential to improve levels of physical activity in those who are predominantly partaking in sedentary technology based activities.

Sports trackers such as the iPod Nike+, Endomondo, Run Keeper, are just a few of the devices available to use whilst exercising. Some of these started their life specifically focused on running but have since opened up to other activities such as cycling, skiing, mountain climbing. Trackers enable sharing and analysis of workouts [25] in addition to recording information such as calories burnt, distance and speed travelled [10]. These trackers do require carrying a GPS enabled device which can be off-putting to some [10].

In using new technologies to help increase activity levels, it is believed that they must be "inexpensive, easy to use, comfortable to wear, durable and reasonably accurate" [21 p.157]. Accuracy is key in order for the user to view a true recording of their efforts and not blame the technology for poor performance. Introducing some form of automated coach with the capability of detecting a decline in the users performance was deemed as a potential solution to keeping users on track and motivated [21]. Working as teams was also believed to be more encouraging than working alone, which is in line with the idea of social support helping to maintain physical activity levels [19].

Endomondo, just one of the trackers available, enables data to be viewed via maps in addition to sharing the information with friends encouraging a competitive arena through formalized competitions and general social competition amongst peers [25]. The use of a GPS tracker enables high accuracy of distance and duration.

The key is to make the technology something that the user will continue to use, rather than discard once the novelty of it has worn off [21].

\section{$5 \quad$ Scoping Study}

The aim of this pilot study was to investigate, at a low level, the potential for new technologies to help encourage individuals to become active through the activity of running. The iPod Nike+, the focus of the pilot study for this paper, was launched in the US in 2006, this has since become more sophisticated but the initial device, described in more detail below, was the one used for the initial scoping project.

The iPod Nike+ kit allowed runners to track miles, speed and duration via a small receiver which fit into their trainer and linked to their iPod. At the end of the run a voice would report the information to the runner in addition to displaying the overall outcome on the screen. The runner could upload their per- 
sonal data to a website in order to track and monitor performance, they could also partake in competitions and challenges posed by the Nike+ team [26, 27].

Working within the Leeds Metropolitan University ethics code of practice the pilot study explored two different data sets with the intention of gaining some initial idea of the potential for the iPod Nike+ kit to encourage individuals to start or continue running.

Data collected via a questionnaire (Data Set 1 ) was explored with the main aim of collecting TTM related information. Data collected from a set of customer reviews (Data Set 2) was investigated to investigate wider issues related to the technology. The customer reviews were posts placed on the Apple iPod Nike+ website [26]. The data sets were reviewed separately and then combined to give an overall perspective of the use of the new technology to support running behavior.

\subsection{Data Set 1 Procedure}

Free iPod Nike+ kits had been distributed to two universities in Leeds, UK, in April 2008 as part of a promotion by Apple and Nike. Kits were distributed from a bus on campus on a first come first served basis. Each person who received a free kit also received a free t-shirt, was registered to the Nike website and also automatically signed up to a Facebook group (376 members in August 2009). The likelihood of the individuals spanning all stages of the TTM was high and this group was therefore deemed suitable to try and recruit participants from. The potential participants were not contacted until a year after the distribution of the kit, thus allowing time for any changes to behavior to occur; the TTM states 6 months before movement to a new stage can occur [28].

The Facebook group was contacted with a questionnaire link, set up using survey monkey. The questionnaire investigated stage of change for prior to receiving the kit and a year after receiving the kit in addition to information about use of the kit itself.

Ideally a pre and post-test would have been preferred, but due to the nature of the launch, this was not possible.

\subsection{Data Set 1 Results}

Unfortunately only 14 respondents answered the questionnaire which whilst very disappointing will still be used to give some insight into the study but with no statistically significant results being claimed.

Nine of the participants claimed that they had noticed an impact on their running behavior, with the remaining 5 claiming that it had no effect. Using the TTM data, 5 respondents showed a change of stage, with one respondent 
moving up two stages. No one showed a relapse or reduction in stage of change with regard to running behavior.

Receiving the data on their performance was highlighted as the most encouraging factor to take the kit with them on their run, followed closely by having a set goal to meet. One of the main reasons for not taking the kit with them was having nowhere to put the iPod.

\subsection{Data Set 2 Procedure}

Customer reviews (298) posted on the Apple iPod Nike+ website [26] were accessed in January 2010. The posts were completed by people who had already purchased the kit and were therefore likely to be in stage 2 of the TTM or above.

Each review was coded via a phrase by phrase technique and then codes were grouped under theme headings. The reviews were treated with caution as it was possible they could have been posted by the company to help promote the kit, however, upon reading the reviews it was deemed unnecessary to be cautious as many contained negative points as well as positive which were unlikely to have been posted by company representatives.

\subsection{Data Set 2 Results}

An overarching element that was clear from all of the comments made in the reviews was that they all had a motivation for running already. The comments ranged from wanting to take up running and using the kit as an encouragement to do so, to using the kit as a tool for maintaining their current running habits, and improving upon already existing running activities.

"[The device] compelled me to run more frequently and with greater purpose than ever before" (Customer Review ID 21)

The comments reviewed verified the initial assumption that those posting comments would all have been in at least stage 2 of the TTM.

Receiving data about their performance through written data in addition to the personalized messages received at the end of the workout were all reported as positive features of the kit.

"During the workout the feedback was great, the voice was nice, and being able to hear my pace/distance/time/calories at the touch of a button was cool. My favourite part has been the Nike+ site which visually shows your runs as a graph over time" (Customer Review ID 182)

Despite some negative comments made throughout the reviews, predominantly with the very poor battery life of the sensor, no one claimed that they were going to stop running or had found that this had reduced their activity levels, if anything the reviews were stating ways around the problems or recommending other similar products that did not have this negative element included. 


\section{Discussion}

Overall the data collected showed a positive report with regard to improvement in running behaviors as a result of the technology. Individuals who answered the questionnaire had claimed that they had moved up at least one stage of change. In some cases respondents from both data sets who were already active runners stated that they had increased the frequency and/or duration of their workouts. Other individuals from data set 2 had purchased the device with the specific aim of using it to help them to start running. This is a positive outcome for using the device to encourage behavioral change. Information from individuals in stage 1 was lacking, which was to be expected from the data that was available to the researchers at the time. This is perhaps an area worthy of future study.

The iPod Nike+ kit offers social support as discussed by Cavallo et al [19] via the Nike website where results and challenges can be exchange via formal competitions and social forums. This adds a community aspect to something that could otherwise be viewed as a very solitary activity.

Goal setting and monitoring performance are obvious features of the device as workout statistics such as duration, distance, and pace are reported back on screen and via a voice message at the end of each workout. The data is also available for viewing as individual runs and as overall performances dating back to the start of using the tracker via the website. Both of these elements were mentioned in both data sets as factors that encouraged the use of the device. The participants saw great benefit in being able to see if they were improving and meeting goals. This fits with research conducted by Rhodes and Pfaeffli [20], Richardson [21] and Nigg [12].

Personalized feedback of data was included in the technology via a sports star reporting when the individual had improved the time for their fastest mile or run a new distance. This aspect was considered an appealing feature by respondents from both data sets which fits with information raised in the literature [12]. The participants enjoyed the idea of being able to hear, from a famous person, how they were improving.

Some of the barriers to the uptake of physical activity, such as tiredness, and other demands [22] cannot immediately be overcome by this specific technology. However barriers such as cost can be addressed by such technologies.

This scoping study shows a positive outcome of using technology such as the iPod Nike+ to help motivate and encourage activity levels with regard to running. Long term effects and any influence on individuals portraying characteristics of stage 1 in the TTM require further investigations. 


\section{$7 \quad$ Further Work}

Taking into account the number of activity led technologies now in existence the authors would like to explore other devices than the iPod Nike+ kit. Whilst the kit has improved since this study was conducted it still has some limiting factors such as the individual requiring an iPod device. Endomondo, a tracker mentioned earlier in the paper, has a wider reach as it is a free app to download to a wide variety of GPS enabled devices. This emphasizes the availability to all aspect that was the emphasis behind the idea of looking at running as an activity.

Factors such as long term impact of the technology on activity behaviors and the capacity to reach individuals in all stages of the TTM need careful consideration in any future research.

\section{References:}

1. World Health Organization: Global Recommendations on Physical Activity for Health. Who Press, Switzerland (2010)

2. Foley, L., Maddison, R.: Use of Active Video Games to Increase Physical Activity in Children: A (Virtual) Reality? Pediatric Exercise Science 22, 7-20 (2010)

3. McPhail, S., Schippers, M.: An evolving perspective on physical activity counselling by medical professionals. BMC Family Practice 13, 1-8 (2012)

4. Jackson, R., Asimakopoulou, K., Scammell, A.: Assessment of the transtheoretical model as used by dietitians in promoting physical activity in people with type 2 diabetes. Journal of Human Nutrition and Dietetics 20, 27-36 (2007)

5. Department of Health: At least five a week. Evidence on the impact of physical activity and its relationship to health. A report from the Chief Medical Officer. Department of Health (2004a)

6. Department of Health: Choosing Health: making healthy choices easier. Public Health White Paper 16/11/04, (2004b)

7. Department of Health: Health benefits of physical activity in childhood and adolescence. At least five a week: Evidence on the impact of physical activity and its relationship to health 29/04/04, 31-35 (2004c)

8. PublicTechnology.net: Sport England uses web as a prime comms tool in its Everyday Sport campaign. (2005)

9. www.nhs.uk/change4life/Pages/change-for-life.aspx

10. Gil-Castineira, F., Costa-Montenegro, E., Gonzalez-Castano, F.J., Lopez-Bravo, C.: Experiences inside the Ubiquitous Oulu Smart City. IEEE Computer 44, 48-55 (2011)

11. Cummings, J., Duncan, E.: Changes in affect and future exercise intentions as a result of exposure to a regular exercise programme using the Wii Fit. Sport and Exercise Psychology Review 6, 31-41 (2010)

12. Nigg, C.R.: Technology's influence on physical activity and exercise science: the present and the future. Psychology of Sport and Exercise 4, 57-65 (2003)

13. Hall, T.: Emplotment, Embodiment, Engagement: Narrative Technology in Support of Physical Education, Sport and Physical Activity. Quest 64, 105-115 (2012) 
14. Kennett, D.J., Worth, N.C., Forbes, C.A.: The Contributions of Rosenbaum's model of self-control and the transtheoretical model to the understanding of exercise behaviour. Psychology of Sport and Exercise 10, 602-608 (2009)

15. Callaghan, P., Eves, F.F., Norman, P., Chang, A.M., Yuk Lung, C.: Applying the Transtheoretical Model of Change to exercise in young Chinese people. British Journal of Health Psychology 7, 267-282 (2002)

16. Grimley, D., Prochaska, J.O., Velicer, W.F., Blais, L.M., DiClemente, C.C.: The Transtheoretical Model of Change. In: Brinthaupt, T.M., Lipka, R.P. (eds.) Changing the Self: Philosophies, Techniques, and Experiences, pp. 201-228. SUNY Press, New York (1994)

17. Prochaska, J.O., DiClemente, C.C.: The transtheoretical approach: Crossing the traditional boundaries of therapy. Krieger Publishing Company, Melbourne, Florida (1984)

18. Pro-change behaviour systems inc, www.prochange.com/ttm

19. Cavallo, D.N., Tate, D., Ries, A.V., Brown, J.D., DeVellis, R.F., Ammerman, A.S.: A Social Media-Based Physical Activity Intervention. American Journal of Preventive Medicine 43, 527-532 (2012)

20. Rhodes, R.E., Pfaeffli, L.A.: Mediators of physical activity behaviour change among adult non-clinical populations: A review up-date. International Journal of Behavioural Nutrition and Physical Activity 7, 37 (2010)

21. Richardson, C.R.: Objective monitoring and automated coaching: a powerful combination in physical activity interventions. Physical Therapy Reviews 15, 154-162 (2010)

22. Burton, N.W., Turrell, G., Oldenburg, B.: Participation in Recreational Physical Activity: Why Do Socioeconomic Groups Differ? Health Education and Behavior 30, 225-244 (2003)

23. Department of Health and Human Services: Physical activity and health: A report of the Surgeon General. US Department of Health and Human Services, Centres for Disease Control and Prevention, National Centre for Chronic Disease Prevention and Health Promotion, Altanta (1996)

24. Fjeldsoe, B.S., MIller, Y.D., Marshall, A.L.: Social Cognitive Mediators of the Effect of the MobileMums Intervention on Physical Activity. Health Psychology (2012)

25. Kjaergaard, M.B.: Location-Based services on Mobile Phones: Minimizing Power Consumption. IEEE Pervasive Computing 11, 67-73 (2012)

26. http://www.apple.com/ipod/nike/,

27. http://nikerunning.nike.com/nikeplus/?sitesrc=GBLP,

28. Cardinal, B.J., Lee, J.-Y., Kim, Y.-H.: Predictors of Transitional Shifts in College Students' Physical Activity Behavior. International Journal of Applied Sports Sciences 22, 24-32 (2010) 